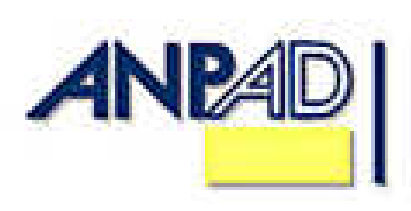

Disponível em http://www.anpad.org.br/rac

RAC, Curitiba, v. 13, n. 2, art. 2, p. 189-209, Abr./Jun. 2009

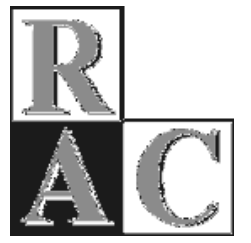

\title{
Jogos de Empresas e Economia Experimental: um Estudo da Racionalidade Organizacional na Tomada de Decisão
}

\section{Business Games and Experimental Economics: a Study of Organizational Rationality in Decision Making}

\begin{abstract}
Antonio Carlos Aidar Sauaia * Doutor em Administração pela FEA/USP. Professor Associado no Departamento de Administração da FEA/USP, São Paulo/SP, Brasil.
\end{abstract}

Sabrina Arruda Zerrenner Mestre em Administração pela FEA/USP, São Paulo/SP, Brasil.

\footnotetext{
* Endereço: Antonio Carlos Aidar Sauaia

Avenida Prof. Luciano Gualberto, 908, FEA1, Sala G160, São Paulo/SP, 05508-900. E-mail: asauaia@usp.br
}

Copyright (C) 2009 RAC. Todos os direitos, inclusive de tradução, são reservados. É permitido citar parte de artigos sem autorização prévia desde que seja identificada a fonte. 


\title{
RESUMO
}

Este artigo contribui, por meio de análise empírica de comportamentos em jogos de empresas, para a discussão das teorias clássicas da tomada de decisão, notadamente os estudos de Simon. Foram produzidos dados primários em jogos de empresas operados como experimentos laboratoriais encadeados. Buscaram-se evidências empíricas de como os indivíduos processam a informação recebida para tomar decisões. Em concordância com os teóricos de economia e finanças comportamentais (Barberis \& Thaler, 2003; Breinholt, Chesteen, \& Cooper, 1992; Shiller, 2000; Simon, 1957, 1976), as escolhas de alguns indivíduos mostraram-se racionais, mas de maneira limitada, produzindo resultados em desacordo com a teoria da utilidade esperada devido a alguns fatores cognitivos (Simon como citado em Bazerman, 2004, p. 6): simplificação; falta de critérios; restrição de tempo e de custo; percepção; capacidade de retenção da memória. As decisões subjetivamente racionais (racionais $a$ priori) que pareciam alinhar meios e fins revelaram-se ineficientes (a posteriori), prejudicando o desempenho da organização (taxa interna de retorno) e reduzindo o incentivo dos gestores (avaliação de desempenho). As evidências aqui relatadas, baseadas em resultados objetivos e observações, abrem caminho para a aproximação entre pesquisas com jogos de empresas e a área de economia experimental.

Palavras-chave: economia experimental; jogos de empresas; racionalidade organizacional; tomada de decisão.

\begin{abstract}
Through the empirical analysis of behavior in business games, this paper contributes to the discussion of the classical theories on decision making, especially the studies of Simon. Primary data from sequential experiments were collected from business games that operated as laboratory experiments. According to the theorists of Experimental Economics and Behavioral Finance (Barberis \& Thaler, 2003; Breinholt, Chesteen, \& Cooper, 1992; Shiller, 2000; Simon, 1957, 1976), there was evidence that the choices of some individuals were rational, although in a limited way, producing results in disagreement with the expected utility theory. Their judgment prevented their organizations from maximizing the results because of some cognitive factors (Simon as cited in Bazerman, 2004, p. 6) such as simplification, lack of criteria, time restriction, cost restriction, perception and the ability to retain information in the memory. The subjectively rational decisions (rational a priori), which seemed to align means and ends, were shown to be inefficient (a posteriori) reducing the organizational performance indicator (internal rate of return) and lowering incentives for the managers (performance evaluation). The evidence shown here, based on objective data and observations, makes it possible to study problems in the field of Experimental Economics through business games.
\end{abstract}

Key words: experimental economics; business games; organizational rationality; decision making. 


\section{INTRODUÇÃO}

As teorias microeconômicas, clássica e neoclássica, consideraram o gestor um agente racional e otimizador, plenamente orientado para o uso eficiente dos recursos escassos. Na academia ressurgiu uma discussão mais recente sobre a eficiência dos mercados concorrenciais, que passou por uma evolução desde quando era considerada provada sem ser posta em dúvida. Em meados dos anos 70 foi retomado o questionamento sobre a consistência dos modelos de mercado eficiente e de suas premissas. O pressuposto de que os indivíduos podiam ser considerados totalmente racionais foi posto em dúvida, recuperando-se a discussão sobre o conceito de racionalidade limitada. Simon estudou o tema e caracterizou alguns limites da racionalidade humana em sua destacada obra Administrative Behavior (1976).

Com o afluxo de novos pesquisadores, "essa linha de pesquisa ganhou enorme audiência entre economistas e, hoje, vários de seus mentores atuam nas principais escolas de Economia e Negócios nos Estados Unidos, como Robert Shiller (Yale), Richard Thaler (Chicago), David Laibson e Andrei Shleifer (Harvard) e James Poterba (MIT)" conforme descreveu Milanez (2003, p. 15) em seu estudo sobre a Teoria de Finanças Comportamentais no Brasil, também conhecida como economia experimental ou psicologia econômica.

No presente estudo, representativo e complexo, inspirado nas idéias de Simon (1976), identificaramse evidências dos limites da racionalidade no comportamento gerencial. Foram conduzidos experimentos encadeados com o auxílio de jogos competitivos, em que se observou e analisou o comportamento de gestores quanto ao entendimento e à prática das regras econômicas de um simulador organizacional. Neste experimento, baseado em jogos de múltiplos estágios e com múltiplas pessoas (Bianchi \& Silva, 2001, pp. 150-151), adotaram-se os seguintes problemas de pesquisa: a) ilustrar o método experimental conduzido em jogos de empresas; b) examinar quais aspectos do comportamento gerencial sinalizam limitações da racionalidade, seja nas ações observadas seja nos resultados objetivos produzidos por gestores em jogos de empresas, a saber, racionalidade objetiva, subjetiva, organizacional e pessoal.

Partindo de situação inicial idêntica, os grupos tomaram decisões econômicas (atividade-meio), tendo por meta maximizar a taxa de retorno sobre o patrimônio líquido e alcançar nota (atividade-fim) para aprovação na disciplina de pós-graduação stricto sensu. Participaram 14 pós-graduandos, sete mestrandos e sete doutorandos que, em duplas, gerenciaram sete empresas concorrentes em busca de desempenho superior e nota. Tal critério de avaliação inibiu as tentativas de os participantes impressionarem favoravelmente os pesquisadores, como adverte Bianchi e Silva (2001), assegurando qualidade aos dados primários.

\section{REVISÃO DA LITERATURA}

\section{Mercado Eficiente e Racionalidade Limitada}

Em Barberis e Thaler (2003, p. 2), a teoria tradicional, que pressupõe o mercado eficiente, tem como paradigma a racionalidade dos agentes do mercado financeiro, ou seja, os agentes, ao receberem novas informações, atualizam suas crenças e fazem escolhas, tomando decisões consistentes com a Teoria da Utilidade Esperada. Na década de 70 os acadêmicos não questionavam a teoria do mercado eficiente, segundo Shiller (2002, p. 2). Os modelos financeiros da época relacionavam especulação dos preços dos ativos com fundamentos econômicos, utilizando expectativas racionais para associar Finanças e Economia. Nos anos 80, com o aumento da volatilidade nos mercados, a academia inicia seus questionamentos sobre a consistência dos modelos de mercado eficiente. Em 1982 a moratória do México levou à crise da dívida dos países emergentes. Nos anos 90 foram introduzidos conceitos de 
psicologia para relacioná-los ao mercado financeiro, desenvolvendo-se o campo de finanças comportamentais.

Shiller (2002, p. 13) afirma que o livro The Econometrics of Financial Markets representa "um extensivo corpo de trabalhos empíricos", sumariados no estudo que "construiu os fundamentos para uma revolução em finanças". Os modelos que consideravam os indivíduos totalmente racionais pareciam não responder integralmente às questões enfrentadas pelos gestores no mundo real. $\mathrm{O}$ estudo do comportamento humano tornou-se mais importante e com ele o conceito de racionalidade limitada.

Em oposição aos defensores da Teoria da Utilidade Esperada, os teóricos de finanças comportamentais, segundo Barberis e Thaler (2003, pp. 2-3), argumentam que alguns fenômenos financeiros podem ser mais bem compreendidos, se os agentes não forem considerados totalmente racionais, como, por exemplo, quando ocorrem as bolhas especulativas no mercado financeiro. Estes autores lembram que em finanças comportamentais há um relaxamento das premissas do paradigma tradicional, ou seja, as crenças não são necessariamente atualizadas de maneira correta, mas sim em função de experiências passadas, percepção sobre fatos e aversão a risco decorrente de perdas anteriores.

Desde 1957 Simon argumentava que o julgamento individual restringe-se pela sua racionalidade (Bazerman, 2004, p. 6). Apesar de tentarem agir racionalmente, os indivíduos são impedidos de tomar decisões ótimas ou maximizadoras devido a certos fatores cognitivos:

1) As restrições de tempo e de custo

2) As limitações de inteligência e de percepção

3) A simplificação ou falta de informações importantes

4) A falta dos critérios relevantes para a resolução do problema

5) As limitações na capacidade de retenção das informações na memória humana.

Para Simon (1976, pp. 76-77) a racionalidade está associada à seleção de comportamentos alternativos preferenciais, baseados em sistemas de valores tais que as consequiências dos comportamentos possam ser avaliadas. Quando um comportamento produz um erro como decorrência de uma informação falha em posse do tomador de decisão, ainda assim ele pode ser considerado racional, quando se acredita no benefício da sua escolha supostamente correta (a priori). Não será assim considerado no caso de, sob teste objetivo (a posteriori), sua escolha mostrar-se ineficaz. Assim, na concepção de Simon, uma decisão é denominada objetivamente racional, se de fato ela resulta do comportamento que maximiza certos valores em determinada situação. É denominada subjetivamente racional, se maximiza o conhecimento sobre o assunto.

Assume outras denominações que explicam os aspectos da racionalidade envolvidos em cada situação: conscientemente racional, quando ajusta os meios aos fins (causa-efeito); deliberadamente racional, quando os ajustes de meios e fins são deliberadamente conduzidos pelo indivíduo ou organização; denomina-se racionalidade organizacional, se orientada para as metas da organização; será racionalidade pessoal, se orientada para as metas do indivíduo. Recomenda Simon que o termo racionalidade seja qualificado por advérbio ou pelo contexto.

\section{Tomada de Decisão Organizacional}

Os gestores nas organizações têm como desafio atender às preferências de diferentes grupos de interesses (acionistas, fornecedores, clientes e concorrentes, entre outros), o que, geralmente, implica lidar com metas conflitantes, limitação de recursos, falta de tempo suficiente para desenvolver e selecionar boas alternativas de decisão. $\mathrm{O}$ acionista, por exemplo, deseja receber dividendos antecipados, enquanto o gestor posterga seu pagamento para dispor de capital de giro e investir em novos projetos. $\mathrm{O}$ fornecedor espera que seu cliente encomende insumos para a produção de maneira 
planejada e regular, respeitando os prazos de fornecimento, enquanto o gestor gostaria de receber os insumos imediatamente após a colocação do pedido de compra, para suprir sua linha de produção. $\mathrm{O}$ cliente demanda produtos de baixo preço e elevado nível de serviço e tecnologia, enquanto o gestor redefine sua política de preço para aumentar a margem de contribuição. Os concorrentes desafiam o mercado, oferecendo novos atributos em busca de fatia adicional, enquanto o gestor gostaria que isto não ocorresse, para manter sua participação de mercado com mínimo esforço. Qualquer que seja o conflito, sua solução culmina com uma escolha ou tomada de decisão.

Para Bazerman (2004, pp. 3-5) a tomada de decisão se caracteriza como processo encadeado que se apóia em aspectos cognitivos de coleta de dados, análise e julgamento. Recomenda que se deve identificar os componentes da decisão para entender o julgamento organizacional. As situações acima descritas têm algo em comum que podem caracterizar a anatomia de uma decisão. Cada uma descreve um problema, ao qual se podem associar várias alternativas de solução. $\mathrm{O}$ autor recomenda seis etapas que geralmente são seguidas, implícita ou explicitamente, para caracterizar um processo racional de tomada de decisão:

1) Definir o problema de maneira clara e explícita - por vezes os gestores agem sem ter um entendimento completo do problema, levando-os a resolverem o problema errado. Erram por definir um problema em termos de uma solução proposta, ou deixam de notar um problema maior, ou ainda diagnosticam o problema por meio dos sintomas. A meta deve ser a solução do problema e não apenas a remoção dos sintomas.

2) Identificar os critérios diferentes e sua importância relativa - os processos de decisão requerem o alcance mais de um objetivo, demandando a identificação de todos eles.

3) Ponderar os critérios - gestores racionais atribuem peso relativo a cada critério para classificá-los e priorizar um deles.

4) Gerar alternativas ou cursos de ação - uma pesquisa adequada de alternativas segue até que o custo ultrapasse o valor das informações adicionadas. Gasta-se, por vezes, muito tempo, gerando alternativas, o que pode criar uma barreira à tomada de decisão.

5) Classificar as alternativas segundo os critérios identificados - nesta difícil etapa devem-se fazer previsões sobre eventos futuros, tentando avaliar as consequiências potenciais de cada escolha segundo os critérios identificados.

6) Identificar a solução otimizante: realizadas as cinco primeiras etapas, esta sexta resultaria teoricamente do julgamento natural baseado nas anteriores.

Para Bazerman (2004, pp. 5-6) as seis etapas nada têm de especial, visto que existe na literatura grande sobreposição dos modelos propostos. Apesar disso o autor lembra que todo o modelo racional é baseado em um conjunto de premissas que determinam como a decisão deve ser tomada, em vez de descrever como ela de fato é tomada, fazendo o contraponto entre modelos normativos e descritivos respectivamente.

Quando se aborda um problema organizacional de um ponto de vista econômico, o objetivo clássico é a maximização de desempenho por meio do uso eficiente dos recursos, enquanto ao se abordar o problema sob enfoque estratégico, o tomador de decisão tem por finalidade vencer seus oponentes. Trata-se de princípios distintos que orientam as ações organizacionais.

Desde 1963 Cyert e March (como citado em Breinholt, Chesteen, \& Cooper, 1992, p. 21) já questionavam se os planejadores podem, deveriam ou conseguem maximizar alguma função econômica de valor ou se eles simplesmente a satisfazem. Para Breinholt et al. (1992, p. 21), pesquisadores experimentais, "é geralmente aceito que eles apenas as satisfazem porque as demandas cognitivas de maximização excedem os limites da racionalidade limitada humana". 
A racionalidade organizacional, orientada para as metas da organização, segundo Lima e Lezana (2005, p. 179), estabelece uma relação de complementaridade com a racionalidade limitada, "na medida em que estabelece um domínio restrito para o seu desenvolvimento". Breinholt et al. (1992, p. 21) afirmaram ainda que, no planejamento, há uma preocupação dos gestores com o movimento do estado presente dos negócios para certos estados futuros; porém, como o futuro é incerto e a informação sobre o presente é incompleta, o planejamento requer premissas sobre a organização e seu ambiente, no presente e no futuro.

\section{Figura 1: Plano de Gestão em Quatro Etapas}

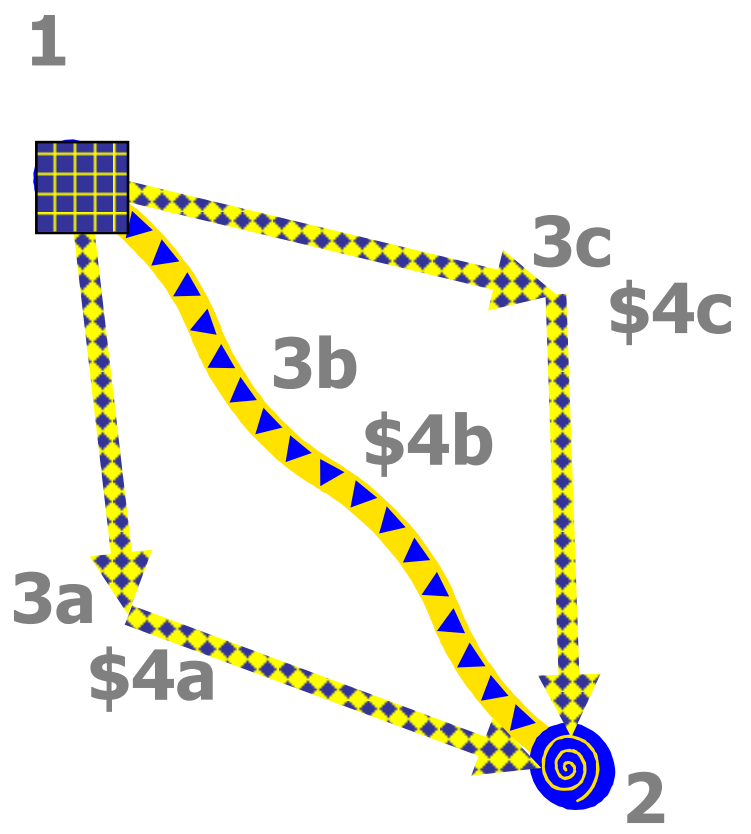

Fonte: adaptado de Sauaia e Sylos (2000, p. 6).

O complexo processo de tomada de decisão organizacional envolve a formulação de uma estratégia que, para ter caráter racional, deve nasce a partir de um plano formal, afirmaram Sauaia e Sylos (2000, p. 6). Os autores propuseram um modelo em quatro etapas (Figura 1), inspirado em diversos estudos, modelo este adotado pelos gestores nos experimentos aqui descritos. Quatro perguntas orientadoras caracterizam o processo a priori, assim enumeradas:

1. Diagnóstico. Onde estamos? Elabora-se uma análise da situação interna e externa baseada no modelo Strengths, Weaknesses, Opportunities, Threats [SWOT], visando identificar e gerenciar pontos fortes e fracos, oportunidade e ameaças.

. Quais os pontos fortes internos da empresa que devem ser alavancados?

. Quais os pontos fracos internos da empresa que devem ser neutralizados?

. Quais as ameaças externas à empresa que devem ser neutralizadas?

. Quais as oportunidades externas à empresa que devem ser exploradas?

2. Objetivos. Para onde iremos? Definem-se objetivos para a organização, levando-se em conta os diversos grupos de interesses, particularmente os acionistas (taxa de retorno). 
3. Políticas e estratégias. Como iremos? Geração de alternativas para aproveitar pontos fortes e oportunidades e neutralizar pontos fracos e ameaças: Estratégias genéricas de Porter: custo total mínimo; diferenciação; enfoque.

4. Orçamento. Metas quantitativas. Quanto recurso financeiro se deve alocar em cada alternativa? Comparar custos e benefícios visando maximizar a utilidade ou retorno.

\section{Jogos de Empresas e Pesquisa Experimental}

O método de aprendizagem vivencial conduzido por meio do jogo de empresas foi utilizado pela primeira vez em 1957 na Universidade de Washington, em um projeto patrocinado pela American Management Association, baseado em jogos militares que tiveram sua origem há aproximadamente 3.000 A.C. na China. A partir deste projeto realizado na Universidade de Washington os jogos de empresas têm sido utilizados para a formação e o treinamento de profissionais ligados à administração de empresas (Sauaia, 1995, pp. 8-9).

Segundo Sauaia (1989, p. 66), "como um exercício de tomada de decisões, os jogos têm por objetivo reproduzir parcialmente e de forma simplificada uma situação que poderia ser real...". Desta forma, por meio dos jogos de empresas, observa-se como os indivíduos processam as informações recebidas e tomam decisões num ambiente similar ao de uma organização.

Nos últimos 30 anos algumas organizações de pesquisadores (ex: Association for Business Simulation and Experiential Learning [ABSEL] nos EUA e International Simulation ad Gamimg Association [ISAGA] na Europa) passaram a adotar os jogos de empresas como ambiente laboratorial para a condução de pesquisa experimental nas áreas de economia, gestão estratégica e organizações (Sauaia, 2006).

Cita-se como exemplo o artigo de Babb, Leslie e Van Slyke (1966) sobre o potencial dos jogos de empresas para a pesquisa. Segundo os autores, os jogos de empresas parecem atender bem aos estudos de estrutura de mercado, atributos psicológicos e outras variáveis que afetam o comportamento das firmas. A vantagem é que as variáveis de interesse podem ser controladas ou identificadas e os resultados podem ser medidos objetivamente, o que seria difícil ou impossível na vida real.

Jogos simulados podem ser usados como ambiente de pesquisa e treinamento, oferecendo vantagens e desvantagens ao se investigar temas importantes (Gentry \& Schibrowsky, 1990, p. 1). Desde o seu surgimento, os jogos simulados propunham este novo paradigma na visão de seus criadores, segundo Cohen e Rhenman (1961). Diversos temas têm sido associados aos jogos: comportamento negocial, planejamento estratégico, propaganda, desinvestimentos, processo decisório, estilos de liderança, preços no varejo, entre tantos outros.

Aplicações de jogos de empresas em estudos experimentais têm sido feitas por pesquisadores em diversas partes do mundo. Dasgupta, Chanin e Ioannidis (2000, p. 536) examinaram o efeito de uma ferramenta de apoio à decisão em grupo, num experimento controlado com jogo de empresas, concluindo que tal ferramenta não pareceu reduzir o conflito intragrupo. Apesar disso o desempenho do grupo experimental foi marginalmente superior, em prejuízo da satisfação de seus membros, submetidos à lógica da ferramenta especialista de tomada de decisão. Rouchier e Robin (2006, p. 195) conduziram uma pesquisa experimental, baseada num leilão contínuo com dois jogadores, observando a alta rapidez com que os preços de negociação convergiram e a baixa importância da memorização das transações passadas na aprendizagem decorrente.

O ensino de Microeconomia tem sido apoiado por simuladores, para complementar a pedagogia tradicional. Cada aluno deve administrar uma empresa que opera sob diferentes estruturas de mercado: concorrência perfeita, oligopólio e monopólio puro. Os resultados das pesquisas têm mostrado uma aprendizagem efetiva, o que torna o simulador uma ferramenta pedagógica a ser seriamente considerada por educadores (Gold \& Strang, 1981, p. 95). 
Wolfe e Castroviovanni (2006, p. 31), em seu estudo, reafirmaram que os jogos de empresas são adequados para prover laboratórios de pesquisa para experimentos controlados em estratégia empresarial. É fato que existem poucas evidências da validade de tal abordagem. Os autores examinaram de que maneira um simulador (The Global Business Game - Wolfe, 2003 como citado em Wolfe \& Castroviovanni, 2006) poderia criar condições laboratoriais para se investigar o paradigma das Contingências Ambientais, sob a ótica conceitual das incertezas de Duncan (1972). Concluíram que, apesar de um determinado simulador e sua aplicação não se terem revelado plenamente apropriados para estudar tal paradigma, poderá ser adequado para estudar outros fenômenos associados aos padrões de aprendizagem e liderança organizacional.

Faria e Wellington (2004, p. 186) estudaram a opinião de usuários antigos e atuais de simuladores de jogos de empresas. Os maiores benefícios para os professores são que os simuladores fornecem exercícios interativos e dinâmicos e permitem a aplicação da teoria. Para os estudantes as três principais vantagens são que os jogos de empresas fornecem aprendizado vivencial, permitem a integração de diferentes áreas funcionais nos cursos ministrados e tornam possível aplicar a teoria em um ambiente prático de tomada de decisão.

Não se pode afirmar que todos os simuladores têm boa qualidade para serem usados na educação gerencial em disciplinas de Política de Negócios. Whitney (1984, p. 258) comparou dois simuladores e constatou que um deles trazia erros graves de programação. Ambos foram submetidos ao teste das três dimensões, que o autor considerou mandatórias: realismo; fácil entendimento; confiabilidade. Qualquer falha em uma dessas dimensões pode prejudicar a aprendizagem. Apesar de necessária alguma abstração do mundo real, os elementos presentes devem ser representados corretamente. Consegue-se, assim, elevar a motivação dos estudantes para utilizarem ferramentas de análise e de síntese, que aprenderam nas disciplinas funcionais, premiando sua correta aplicação. Para o autor um simulador deve ser claro o suficiente para que não se gaste muito tempo aprendendo suas regras em lugar de aplicar os conceitos fundamentais. A situação econômica representada deve trazer paralelismo com a realidade, para promover o entendimento das relações. Além das três características obrigatórias, há outras desejáveis num simulador: manual do usuário claro e completo; nível de complexidade ajustável; diferentes ambientes para a escolha do administrador do jogo.

No Brasil os estudos com jogos de empresas têm início na década de 70 com Tanabe (1973) e prosseguem nas décadas seguintes com as contribuições de Martinelli (1987), Beppu (1984) e Sauaia (1989). Este último autor desenvolve o tema e publica a primeira tese brasileira de doutorado (Sauaia, 1995), baseada em pesquisa de opinião de 659 respondentes, para verificar o binômio satisfaçãoaprendizagem em jogos de empresas conduzidos sob diferentes formatos, para públicos distintos, acadêmicos e profissionais.

Para contornar os aspectos subjetivos típicos das pesquisas de opinião, Sauaia (2003) inicia um projeto de pesquisas experimentais, produzindo dados primários mais robustos, baseados na observação do comportamento gerencial e nos resultados dos jogos de empresas. Na pesquisa experimental as variáveis são manipuladas de maneira preestabelecida, com efeitos suficientemente controlados, na busca de relações causais (Martins, 2002, p. 35). O método experimental, de acordo com Lakatos e Marconi (1988, p. 19), tem como objetivo "a aplicação, a modificação e/ou a mudança de alguma situação ou fenômeno".

Na primeira versão da pesquisa experimental de Sauaia (2003) indagou-se a existência de correlação entre conhecimento individual dos jogadores e o desempenho coletivo alcançado pelos grupos de competição. A premissa testada partiu do pressuposto de que jogadores com mais conhecimentos, certificados pelo histórico escolar, poderiam tomar decisões mais próximas da racionalidade plena e maximizar a utilidade esperada, medida pela taxa de retorno. As versões brasileiras do estudo bem como as internacionais convergem para concluir pela inexistência de correlação entre conhecimento individual e desempenho organizacional.

Em face da surpresa gerada pelos resultados, as pesquisas brasileiras têm avançado e incorporado novas dimensões de estudo, a partir de uma diversidade de temas propostos por pesquisadores que se 
aproximam do grupo de estudos SIMULAB. Este projeto que opera na FEA/USP/SP tem por finalidade desenhar e conduzir pesquisas com jogos empresariais, aproximando as áreas de educação gerencial, de organizações, de estratégia e de economia experimental.

\section{DesenVOlVIMENTO DA PESQUISA}

\section{Procedimentos Metodológicos}

Quando se trata de pesquisa do tipo experimento, como este estudo, o pesquisador educacional tem à mão a clássica obra de Campbell e Stanley (1979, pp. 1-7), que orienta com rigor os procedimentos metodológicos. No método científico denominado experimento, são manipuladas algumas variáveis de interesse, qualitativas ou quantitativas, e observados seus efeitos sobre outras variáveis em estudo. Por meio da análise dos resultados e observações inferem-se possíveis relações de causa e efeito, que levam a conclusões aceitáveis. Os resultados da experimentação em geral não são considerados definitivos. Para melhorar sua qualidade e a qualidade das conclusões, é costume aumentar a perspectiva temporal de observação, reconhecendo que a experimentação contínua e múltipla é mais tipicamente científica. Os estudos podem ainda ser multivariados, isto é, com mais de uma variável independente (sexo, escolaridade, método de ensino, estilo etc.); ou ainda mais de uma variável dependente: número de erros, rapidez, número de respostas certas, vários testes etc.

Com base no método experimental acima descrito, foi conduzido um estudo descritivo e exploratório, tomando-se por base os dados qualitativos e quantitativos produzidos por sujeitos regularmente matriculados em um curso stricto sensu de pós-graduação em Administração. O modelo e as técnicas de pesquisa estão detalhados a seguir, oferecendo uma visão minuciosa das duas etapas dos procedimentos experimentais: a primeira etapa ou preparatória (aprendizagem e classificação dos gestores) e da segunda etapa em que efetivamente se deu a coleta de dados primários (dados de desempenho e comportamento gerencial).

\section{Modelo de Pesquisa}

A Figura 2 ilustra o desenho da pesquisa, destacando as duas etapas no estudo. Na primeira pretendeu-se promover aprendizagem dinâmica e individual das regras do simulador (jogo J1 e seminário S1). Classificados por desempenho na primeira etapa, os indivíduos foram agrupados em duplas na segunda etapa. Foi observado o comportamento dos agentes e resultados produzidos nos experimentos encadeados (J2, J3 e J4). Diversos vieses de julgamento foram identificados no comportamento das duplas e parecem ter interferido nos resultados objetivos, afetando o desempenho econômico das organizações e suas notas.

Figura 2: Influências Observadas quanto à Racionalidade Organizacional (Autores)

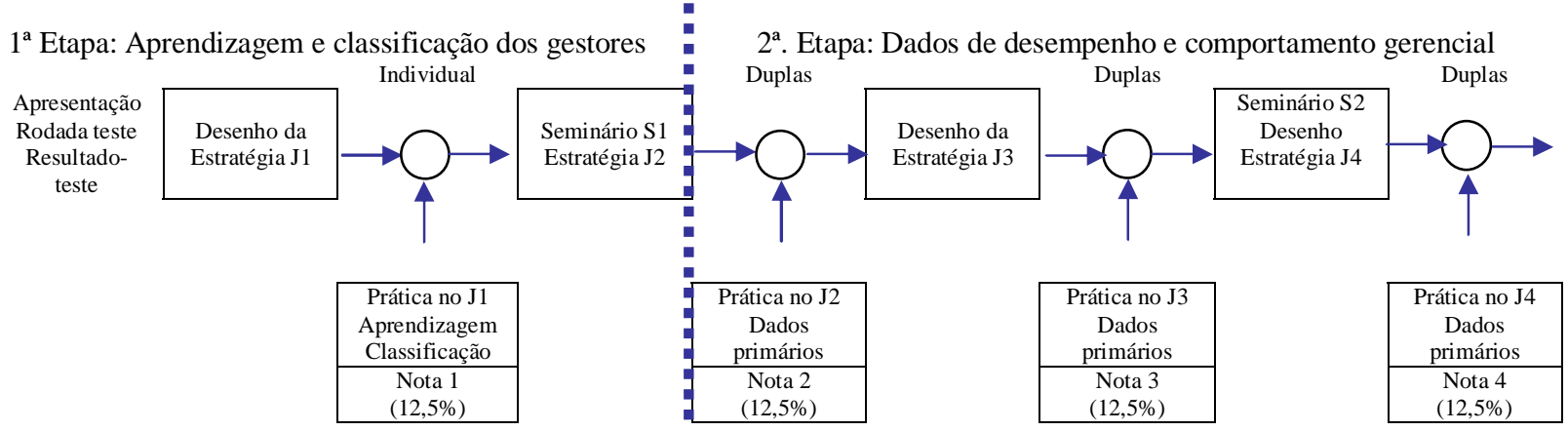

Legenda: Jn - jogos seqüenciais $1 ; \mathrm{Sn}$ - seminários para compartilhar conhecimentos. 
Este estudo apoiou-se em pesquisa descritiva, análise qualitativa e quantitativa baseada em dados e observações coletados nos experimentos controlados. Os participantes perseguiam dois objetivos: o desempenho nos jogos de empresas valia $50 \%$ da nota final na disciplina; a outra metade da nota dependia de elaboração e apresentação de um artigo individual diretamente relacionado ao experimento. As notas foram atribuídas conforme a classificação baseada na taxa interna de retorno. A cada trimestre o primeiro colocado recebeu nota 10, o segundo 9,5, o terceiro 9 até o sétimo receber nota 7. As notas trimestrais parciais geradas a cada rodada produziram uma média simples no final de cada jogo, tendo os quatro jogos ( $\mathrm{J} 1, \mathrm{~J} 2$, J3 e J4) produzido quatro notas (notas 1 a 4) com o mesmo peso relativo $(12,5 \%)$.

\section{Descrição do Experimento}

O ambiente geral do jogo de empresas no Laboratório de Gestão Empresarial tratava da gestão sistêmica de uma empresa sob a ótica das diversas áreas funcionais: planejamento, marketing, produção, recursos humanos, finanças e presidência. Os gestores de cada empresa eram responsáveis por cobrir todas as áreas, para integrar as políticas funcionais com vistas a alcançar o melhor resultado econômico (TIR). O texto inicial, com as regras econômicas do simulador, descrevia uma empresa industrial produzindo e comercializando um bem de consumo em ambiente doméstico. Trazia relatórios gerenciais com resultados quantitativos do trimestre encerrado, apresentados no Demonstrativo Operacional, de Mercado e em três demonstrativos financeiros, a saber: Demonstrativo de Resultados, Demonstrativo de Fluxo de Caixa e Balanço Patrimonial. As regras econômicas cobriram o macroambiente (índices econômicos) e o microambiente (estrutura da indústria semelhante a um oligopólio fechado). A Tabela 1 reúne as variáveis de decisão, as regras e as respectivas restrições.

\section{Tabela 1: Variáveis de Decisão do Simulador, Regras Econômicas e Restrições a Gerenciar}

\begin{tabular}{|l|l|}
\hline \multicolumn{1}{|c|}{ Variáveis de Decisão trimestrais } & \multicolumn{1}{c|}{ Regras econômicas e restriçães } \\
\hline Preço unitário do produto & Efeitos no curto prazo \\
\hline Gastos em Marketing (propaganda, distribuição e comercialização) & Efeitos no curto e médio prazo \\
\hline Gastos c/ P\&D (melhorias tecnológicas graduais - produto/processo) & Efeitos no curto, médio e longo prazo \\
\hline Gastos com Manutenção (processo de produção) & Efeitos imediatos sobre custos diretos \\
\hline Produção programada (depende de matéria-prima e equipamentos) & Limitada pelos fatores de produção \\
\hline Investimento em Equipamentos (amplia a capacidade da planta) & Leva 90 dias para estar operacional \\
\hline Compra de Matéria-prima (fornecedor estatal monopolista) & Leva 90 dias para receber o pedido \\
\hline Distribuição de dividendos (limitada aos lucros retidos) & Afeta o cálculo da taxa de retorno \\
\hline Outros gastos (inteligência competitiva, consultoria e informações) & Aquisição de dados para decisão \\
\hline
\end{tabular}

Todos receberam, no início do experimento, a mesma informação transcrita nos materiais didáticos. Foi conduzida uma apresentação do caso empresarial e das regras de funcionamento da empresa modelada, seguida por uma rodada teste, sem valer nota. Durante o jogo as empresas podiam pagar por serviços de consultoria oferecidos pelo professor, sempre que houvesse uma dúvida operacional associada às regras econômicas do simulador. Quando se tratava de dúvida estratégica, o professor ajudava a desenvolver as alternativas, ficando a escolha por conta dos alunos. Tendo em vista que o desempenho econômico valia nota sob competição, nada foi oferecido gratuitamente, tendo sido cobrados todos os atendimentos.

De início foi declarado que as empresas comercializavam produtos homogêneos, muito sensíveis a preço. Havia no balanço um elevado saldo de caixa ocioso ( 10\% do PL), impondo custo de oportunidade. A planta estava operando em turno normal de produção, sem a utilização de horas extras. O elevado volume de MP em estoque era suficiente para operar 1,5 trimestre. Finalmente, observavam-se produtos acabados em estoque como decorrência de oferta excessiva, não absorvida pelo mercado no período anterior. Foi mencionado que o fornecedor de matéria-prima se constituia de uma empresa estatal monopolista. Deste fato decorriam duas consequiências que sinalizavam a 
necessidade de um cuidadoso planejamento de compras: o custo da matéria-prima teria crescimento ligeiramente inferior à inflação, fato favorável às empresas; a matéria-prima encomendada no início de um trimestre seria entregue na condição CIF (incluindo custo de frete e seguro de transporte) no final do mesmo trimestre, para ser usada no início do trimestre seguinte. Tais dados interpretados e classificados pela inteligência estratégica dos grupos sinalizariam oportunidades ou ameaças.

No final da primeira apresentação (01/06), que incluiu uma rodada teste, foi solicitada a elaboração de um plano de gestão individual. Cada participante gerenciou uma empresa em quatro jogos sucessivos, sendo o primeiro classificatório para os demais.

Para o jogo J1 (08/06 e 15/06) duas indústrias independentes foram formadas: na indústria A foram agrupados os sete mestrandos; na indústria $\mathrm{B}$, os sete doutorandos. Observou-se elevado envolvimento dos participantes nos jogos, dado que o desempenho valia $50 \%$ da nota final. Os resultados do jogo $\mathrm{J} 1$ não foram usados como dados primários. $O$ jogo teve a finalidade de treinar e classificar individualmente os participantes e associar, em cada dupla, níveis similares de assimilação das regras, em face do problema dinâmico proposto pelo simulador.

No término do jogo $\mathrm{J} 1$ foi fornecida uma estrutura para análise dos resultados trimestrais em cada empresa. Tendo em vista que a TIR é um indicador agregado, foram sugeridos três indicadores parciais de eficiência mercadológica (demanda criada vs. demanda atendida), eficiência operacional (capacidade utilizada vs. capacidade instalada) e eficiência financeira (ociosidade dos ativos financeiros). A primeira etapa (aprendizagem e classificação) se encerrou com um seminário aberto (22/06) S1 durante 2 horas, conduzido pelos mestrandos da indústria A, com perguntas livres ao professor e aos doutorandos da indústria $\mathrm{B}$.

Para a segunda etapa (coleta de dados) foram formadas duplas criadas a partir do desempenho individual no jogo J1. Com o intuito de concentrar inteligência e racionalidade nas duplas, os primeiros colocados no jogo $\mathrm{J} 1$ constituíram a dupla 1, os segundos a dupla 2 e assim por diante. Antecedeu o jogo J2 a elaboração de um novo Plano em quatro etapas para quatro trimestres (22/06), tendo sido anunciada a repetição do cenário econômico do jogo J1. Tais planos tiveram processados os quatro trimestres (orçamento de metas), sem que as duplas pudessem revisá-lo trimestralmente (jogo $\mathrm{J} 2$ ). Os resultados do $\mathrm{J} 2$ foram analisados propiciando aprendizagem e revisão do plano, dando início ao jogo J3 (29/06), agora com feedback e controle no final de cada trimestre.

No jogo J3 as duplas operaram por quatro trimestres (T01 a T04), sob os mesmos parâmetros econômicos dos jogos J1 e J2 e, em seguida, por mais quatro trimestres (T05 a T08 - segundo exercício fiscal), sob novo cenário econômico sujeito a maiores incertezas. O J3 produziu os dados primários e as observações, objeto de análise. O sucesso das duplas no jogo J3 - a máxima taxa interna de retorno - foi adotado neste estudo como o indicador objetivo de racionalidade organizacional. Foram também observados no comportamento das duplas outros aspectos da racionalidade (objetiva, subjetiva) mencionados por Simon (1976). No final do J3, foi conduzido pelas duplas um novo seminário S2 (03, 10 e 17/08), analisando-se os dois anos de operações das sete empresas e compartilhando-se a aprendizagem entre todos os jogadores. No término do seminário S2 as duplas elaboraram novo plano para os quatro primeiros trimestres e submeteram um conjunto final de decisões (24/08). Tais decisões foram processadas integralmente, sem que houvesse a possibilidade de revisão por parte das duplas e produziram os resultados do jogo J4, divulgados na semana 12.

\section{Análise Descritiva e Discussão}

O comportamento racional esperado na tomada de decisão levaria os gestores a detectar, a partir da análise SWOT, novas características no ambiente que pudessem afetar significativamente a empresa no futuro. Seria desejável que fossem percebidos e interpretados com propriedade os sinais do cenário econômico que apontassem oportunidades e ameaças.

O principal objetivo a perseguir era a maximização da nota, diretamente associado à expectativa dos investidores, ou seja, a maximização do retorno do acionista (Taxa Interna de Retorno [TIR]). As 
políticas deveriam reconhecer a condição inicial da empresa que produzia e comercializava um produto homogêneo. Partindo de entendimento amplo da condição inicial, restaria estabelecer um orçamento de metas capaz de gerar caixa em consonância com o ciclo da indústria, permitindo antecipação de qualquer natureza.

Tendo em vista o conceito de racionalidade limitada, proposto por Simon (1976), tais cuidados serão irremediavelmente incompletos e diversas variáveis do ambiente das empresas serão negligenciadas. Ademais, Simon (1976) destaca a importância da comunicação, e chama a atenção para a necessidade de disseminar por toda a organização as premissas básicas do plano estratégico, para que este seja efetivo.

No experimento as organizações eram constituídas por duplas de gestores que concentravam em suas mãos todas as atividades organizacionais. Manterem-se plenamente informadas das estratégias era essencial para as duplas, tendo em vista que na ausência de um membro poderiam surgir crises devidas à falta de dados e à ameaça na continuidade da gestão.

\section{Percepção e Racionalidade na Formulação da Estratégia (Análise SWOT)}

Os dados produzidos pelas sete duplas extraídos do Plano 2, na etapa de diagnóstico, foram baseados nos dados iniciais contidos no manual do jogador (Sauaia, 2005, pp. 5-32) e na aprendizagem propiciada pelo jogo J1, preparatória para os jogos J2 e J3. Vale destacar que o Plano 3 diferiu do Plano 2 somente nos dados quantitativos contidos no Orçamento de Metas, tendo sido mantida inalterada a análise SWOT de cunho qualitativo.

Tabela 2: Análise SWOT: Ambiente Interno (Dados Coletados ao Início do Jogo J2)

\begin{tabular}{|c|c|c|}
\hline Grupo & Pontos Fortes & Pontos Fracos \\
\hline 1 & $\begin{array}{l}\text { - Existe um caixa bem grande, o que permite investimentos } \\
\text { - Existe matéria-prima em excesso }\end{array}$ & $\begin{array}{l}\text { - Capacidade de Produção inibe qualquer } \\
\text { estratégia inicial muito agressiva. }\end{array}$ \\
\hline 2 & $\begin{array}{l}\text { - Margem de lucro unitário permite reduções de preço para } \\
\text { tornar o produto competitivo no curto prazo. } \\
\text { - Caixa disponível para investir em P\&D para diferenciar o } \\
\text { produto e em Marketing para alavancar vendas. }\end{array}$ & $\begin{array}{l}\text { - Produto não diferenciado no mercado, } \\
\text { não sendo um diferencial competitivo. } \\
\text { - Preço padronizado no mercado. } \\
\text { - Oferta e demanda não equilibradas. }\end{array}$ \\
\hline 3 & \multicolumn{2}{|c|}{$\begin{array}{l}\text { - Caixa positivo em \$1.377.052; - Aprendizado no ano anterior dos dois sócios. } \\
\text { - Capacidade Produtiva; Inovação no produto; Estoque inicial de matéria-prima. }\end{array}$} \\
\hline 4 & $\begin{array}{l}\text { - A empresa tem executivos experientes (primeiro jogo) } \\
\text { - Pode aumentar em } 50 \% \text { a capacidade produtiva hora-extra }\end{array}$ & $\begin{array}{l}\text { - Capacidade instalada baixa, frente à } \\
\text { demanda prevista. }\end{array}$ \\
\hline 5 & $\begin{array}{l}\text { - Potencial de Investimento. } \\
\text { - Capacidade Intelectual dos sócios. }\end{array}$ & $\begin{array}{l}\text { - Estrutura de produção boa } \\
\text { - Produto parece competir só por preço. }\end{array}$ \\
\hline 6 & $\begin{array}{l}\text { - Possui um consolidado departamento de P\&D. } \\
\text { - Possui conhecimento dos mercados em que atua. }\end{array}$ & $\begin{array}{l}\text { - Estrutura organizacional ainda muito } \\
\text { verticalizada para sustentar agilmente as } \\
\text { demandas de mercado. }\end{array}$ \\
\hline 7 & Não entregou um diagnóstico formal & Não entregou um diagnóstico formal \\
\hline
\end{tabular}

O exame das Tabelas 2 e 3 revela que após quatro semanas de preparação persistiam falhas de conceito, de entendimento das regras econômicas do simulador e de interpretação dos dados iniciais, claras evidências de limitação da racionalidade organizacional. Para ilustrar tais limitações foram destacados e classificados os vieses nos comentários a seguir.

O excedente de caixa no valor de $\$ 1.047 .000$ inicialmente disponível no balanço das empresas (Sauaia, 2006, p. 31) foi classificado por alguns grupos (1, 2 e 5) como Ponto Forte em face da liquidez que representava (Tabela 2), mas sem levar em conta o custo de oportunidade do caixa sem remuneração financeira. O grupo (1) classificou como Oportunidade (Tabela 3) o excesso de caixa ... e o excesso de matéria-prima ...., contrariando o conceito de Oportunidade que se refere aos aspectos do ambiente externo das empresas, sendo o saldo de caixa um elemento do ambiente interno (pontos 
fortes e fracos). Na categoria de Oportunidades o grupo (1) incluiu o excesso de matéria-prima disponível no estoque inicial. Nenhum dos grupos apontou o excesso de caixa como ponto fraco, visto que de fato o capital se encontrava ocioso, implicando custo de oportunidade para a empresa.

O grupo (3), ao realizar o diagnóstico, aglutinou conceitos que são, por definição, opostos entre si, visto que não discriminou os pontos fortes dos fracos (Tabela 2), nem as ameaças das oportunidades (Tabela 3), em sua análise SWOT. Classificou corretamente o aprendizado do ano anterior nas características do ambiente interno, mas apontou saldo de caixa maior que o disponível. Tal erro foi reconfirmado durante o seminário $\mathrm{S} 2$, quando o grupo declarou que ignorava o custo de oportunidade ao manter elevado o caixa. Ao perceber tal deficiência, o grupo corrigiu a análise na revisão do diagnóstico realizada no final das oito rodadas, reconhecendo no plano $\mathrm{P} 4$ o ponto fraco que poderia ter sido percebido desde o início. Para Simon (1976) as observações acima revelam erros de percepção na leitura dos dados.

O grupo (2) classificou como ponto fraco oferta e demanda não equilibradas. Tal equilíbrio envolve aspectos do ambiente externo, não podendo ser considerado ponto fraco, mas ameaça ao sucesso da empresa. Para Simon (1976, p. 75) essa anomalia pode dever-se à falta de critérios relevantes para as análises.

Enquanto os grupos 3, 5 e 6 sinalizavam o conhecimento anterior como ponto forte, o grupo 6 acreditava contar com um consolidado departamento de $\mathbf{P} \& \mathbf{D}$, o que não se observava na prática, revelando-se um viés devido à influência de experiências passadas. Vale lembrar que, ao ser reiniciado o jogo, o histórico das empresas (até mesmo os investimentos em P\&D) era apagado da base de dados, recolocando-as em situação idêntica. Simon (1976, p. 75) destaca as limitações devidas à capacidade de retenção das informações na memória.

A empresa 2 apontou como ameaça (Tabela 3) a possibilidade da prática de dumping. Segundo dados do livro, que todos os participantes receberam no início do jogo, afirma-se no texto que "o preço mínimo admitido pelo sistema é o valor do custo unitário variável" (Sauaia, 2006, p. 25), não sendo possível a prática de dumping, segundo as regras econômicas modeladas no simulador. Considerandose que nos materiais didáticos e na apresentação nada havia que sinalizasse a ameaça de dumping, entende-se que tal conteúdo pode ter sido trazido ao jogo de empresas no conjunto de experiências passadas e percepções viesadas sobre os fatos e que confirmam as expectativas de Simon (1976) e de Barberis e Thaler (2003, pp. 2-3). 
Tabela 3: Análise SWOT: Ambiente Externo (Dados Coletados ao Início do Jogo J2)

\begin{tabular}{|c|c|c|}
\hline Equipe & Oportunidades & Ameaças \\
\hline 1 & $\begin{array}{l}\text { - O excesso de caixa deve ser utilizado } \\
\text { - O excesso de matéria-prima deve ser utilizado para obter } \\
\text { maior volume de vendas nos dois primeiros trimestres. }\end{array}$ & $\begin{array}{l}\text { - Desconhecimento do comportamento } \\
\text { dos adversários no que se refere aos } \\
\text { preços. }\end{array}$ \\
\hline 2 & $\begin{array}{l}\text { - Consumidor sensível a preço no curto prazo. } \\
\text { - Consumidor sensível a diferenciação no médio e longo } \\
\text { prazo. } \\
\text { - Mercado com atividade econômica crescente. }\end{array}$ & $\begin{array}{l}\text { - Mercado oligopolista totalmente opaco. } \\
\text { - Alta rivalidade entre as empresas, } \\
\text { iniciando uma guerra de preço. } \\
\text { - Formação de cartéis, trustes ou prática } \\
\text { de dumping por algumas rivais, tornando } \\
\text { a concorrência desleal. }\end{array}$ \\
\hline 3 & \multicolumn{2}{|c|}{$\begin{array}{l}\text { - Demanda de mercado; Concorrência (preços predatórios) } \\
\text { - Sazonalidade - Alto investimento na capacidade produtiva. }\end{array}$} \\
\hline 4 & $\begin{array}{l}\text { - Houve uma convergência de preços nas rodadas finais } \\
\text { na indústria que se mostrou mais lucrativa (B). É provável } \\
\text { que o preço inicial dos concorrentes seja próximo disso. } \\
\text { Prevendo-se isto, pode-se tentar uma estratégia ousada de } \\
\text { preço e ganhar participação de mercado. }\end{array}$ & $\begin{array}{l}\text { - Três trimestres no escuro, estratégias } \\
\text { ousada ficam ainda mais arriscadas. }\end{array}$ \\
\hline 5 & $\begin{array}{l}\text { - Demanda de mercado boa. } \\
\text { - Mercado sensível a novas tecnologias. }\end{array}$ & - Sazonalidade. \\
\hline 6 & $\begin{array}{l}\text { - Aumento da horizontalização dos negócios por adoção } \\
\text { de tecnologia wireless para interagir com outras empresas } \\
\text { e ampliar o número de parceiros (rede de valor) }\end{array}$ & - Novos entrantes no mesmo mercado. \\
\hline 7 & Não formalizou diagnóstico & Não formalizou diagnóstico \\
\hline
\end{tabular}

Na Tabela 3 observa-se que a sazonalidade foi indicada como ameaça pelo grupo (5), o que torna a análise excessivamente simplista, segundo Simon (1976), visto que havia períodos favoráveis de crescimento sazonal e desfavoráveis de queda da sazonalidade. O grupo (6) classificou como ameaça a possibilidade de novos entrantes, tendo sido declarado no início do experimento que se tratava de um exercício em oligopólio fechado, sem a ameaça de entrantes e sem a possibilidade de saída. O teor desta análise sugere interferência de experiências passadas (Barberis \& Thaler, 2003, pp. 2-3).

Apesar de estimulado, o grupo (7) não redigiu um plano de gestão formal. Limitou-se a preencher e entregar os formulários de decisão a cada rodada, apenas analisando os resultados da rodada anterior. A dupla não fez uso de planilha eletrônica, como seus concorrentes, apenas fazendo uso de calculadoras. Aparentemente não tentou antecipar o futuro ou desenvolver alternativas, antes de implementar uma estratégia. Talvez por isso os resultados inicialmente superiores (líderes em taxa de retorno no trimestre 1) tenham declinado nas rodadas seguintes, conforme a evolução das colocações nos oito períodos: $1^{\mathrm{o}} ; 4^{\mathrm{o}} ; 3^{\mathrm{o}} ; 4^{\mathrm{o}} ; 4^{\mathrm{o}} ; 5^{\mathrm{o}} ; 4^{\mathrm{o}} ; 3^{\mathrm{o}}$.

\section{Decisões e Desempenho na Implementação da Estratégia}

A taxa interna de retorno classificou o desempenho agregado das sete empresas no final de cada trimestre (Tabela 4) e atribuiu-lhes as notas. Seria natural supor-se que as duplas formadas por indivíduos com desempenho individual superior seriam capazes de repetir o sucesso anterior. $\mathrm{O}$ melhor desempenho trimestral está destacado em negrito na Tabela 4. Nota-se que, apesar do cenário econômico no primeiro ano ter sido repetido nos quatro jogos, ocorreu maior variabilidade da liderança ( $1^{\circ}$ Lugar) no decorrer do primeiro ano, estabilizando-se os desempenhos ao longo do segundo ano. Os gestores da dupla 7 com o menor desempenho individual no jogo J1 começaram o jogo J3 na primeira colocação, contrariando a idéia de que as experiências anteriores proveriam um baixo nível de racionalidade. Nos demais períodos tiveram uma queda e estabilizaram seu desempenho entre o terceiro e quinto lugares. 
Tabela 4: Taxas de Retorno Trimestrais e Colocação a Cada Trimestre no J3

\begin{tabular}{|c|c|c|c|c|c|c|c|c|}
\hline Grupo & Trim. I & Trim. II & Trim. III & Trim. IV & Trim. V & Trim. VI & Trim.VII & T. VIII \\
\hline $\mathbf{1}$ & $1,04 \%-7$ & $\mathbf{2 , 3 2 \% - 1}$ & $1,83 \%-5$ & $2,18 \%-5$ & $2,22 \%-5$ & $2,56 \%-4$ & $1,33 \%-6$ & $1,36 \%-4$ \\
\hline $\mathbf{2}$ & $1,28 \%-5$ & $2,26 \%-2$ & $2,19 \%-2$ & $\mathbf{2 , 6 4 \% - 1}$ & $\mathbf{2 , 7 7 \% - 1}$ & $\mathbf{3 , 1 5 \% - 1}$ & $\mathbf{2 , 6 1 \% - 1}$ & $\mathbf{2 , 6 5 \% - 1}$ \\
\hline $\mathbf{3}$ & $1,43 \%-2$ & $2,30 \%-3$ & $\mathbf{2 , 4 4 \% - 1}$ & $2,63 \%-2$ & $2,67 \%-3$ & $2,86 \%-3$ & $1,37 \%-5$ & $1,34 \%-5$ \\
\hline $\mathbf{4}$ & $1,14 \%-6$ & $1,90 \%-5$ & $1,94 \%-4$ & $2,53 \%-3$ & $2,72 \%-2$ & $3,04 \%-2$ & $1,31 \%-7$ & $0,78 \%-7$ \\
\hline $\mathbf{5}$ & $1,32 \%-4$ & $1,45 \%-6$ & $1,06 \%-7$ & $0,84 \%-7$ & $1,34 \%-7$ & $2,17 \%-7$ & $2,05 \%-3$ & $2,07 \%-2$ \\
\hline $\mathbf{6}$ & $1,39 \%-3$ & $1,44 \%-7$ & $1,64 \%-6$ & $1,74 \%-6$ & $1,99 \%-6$ & $2,32 \%-6$ & $2,19 \% 2-$ & $1,29 \%-6$ \\
\hline $\mathbf{7}$ & $\mathbf{2 , 0 0 \%}-\mathbf{1}$ & $2,09 \%-4$ & $2,14 \%-3$ & $2,21 \%-4$ & $2,23 \%-4$ & $2,37 \%-5$ & $1,72 \%-4$ & $1,56 \%-3$ \\
\hline
\end{tabular}

Obs: negrito para o melhor desempenho trimestral.

Em oposição, os gestores da dupla 1, que tiveram o melhor desempenho no jogo J1, alcançaram no jogo J3 o pior desempenho no primeiro período, evoluindo para o primeiro lugar no segundo período e oscilando entre o quarto e sexto lugares. A dupla 2, após oscilar entre o quinto e o segundo lugares, assumiu a liderança no quarto período, ali permanecendo até o último período. A dupla 5, após oscilar entre a quarta e sexta posições, caiu para o último lugar em função de erros sistemáticos, que só foram revertidos mediante a contratação de consultoria paga, terminando sua gestão na segunda colocação.

Ao se examinar a Figura 3, se pode observar o crescimento regular das taxas de retorno das sete concorrentes nos primeiros seis trimestres, tendo em vista as condições econômicas favoráveis e menor grau de incerteza. A posição relativa das empresas sugere que as que erraram menos conseguiram melhores posições. As quedas bruscas de desempenho sinalizam acidentes de percurso resultantes de vieses de julgamento, falhas de gestão ou incidentes críticos trazidos pelo professor. $\mathrm{O}$ grupo 5 cometeu um grave erro sistemático por quatro trimestres consecutivos, o que lhe conferiu a última posição até o trimestre T06. Tais falhas recorrentes produziram aprendizagem na dupla 5, que terminou o trimestre T08 na segunda colocação. Pelo contrário, a dupla 4, que esteve entre os líderes até o T06, terminou em último.

Figura 3: Evolução Gráfica Trimestral das Taxas de Retorno sobre o Patrimônio Líquido.

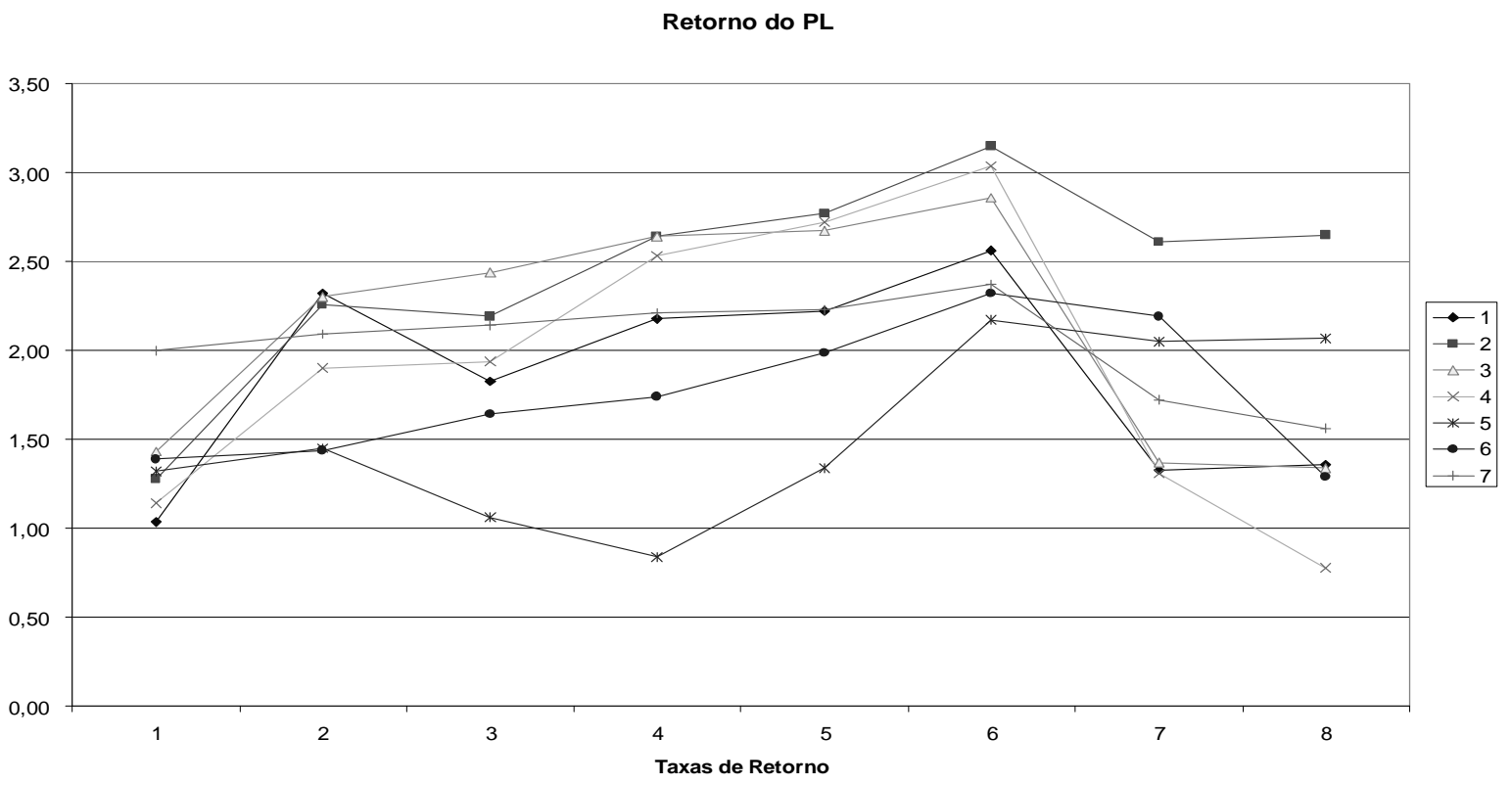

Durante o seminário S2, conduzido pelos gestores no final do jogo $\mathrm{J} 3$, foram produzidos dados adicionais que descreveram as melhores e piores práticas na implementação das estratégias. O grupo 5 
declarou ter percebido incorretamente, durante o jogo, que seu estoque de produtos acabados estava apresentado em unidades físicas, apesar de o Balanço Patrimonial indicar o valor monetário dos produtos em estoque. Isto fez a equipe pressupor capacidade de oferta suficiente para o período seguinte (matéria-prima + produtos acabados). Tal premissa equivocada induziu a tomada de decisões ineficientes, restringindo a produção do período seguinte. A falta de matéria-prima só foi percebida no final do trimestre seguinte, quando a produção programada não se realizou, frustrando as vendas, o lucro e o retorno. Tal fato parece ter produzido aprendizagem, tendo em vista que tal situação não mais se repetiu. Simon (1976, pp.76-77) classifica tal decisão como subjetivamente racional.

Os grupos 3 e 7 mantiveram níveis elevados de caixa; porém por motivos diferentes. O grupo 3 declarou desconhecimento dos custos de oportunidade, o que sugere falta de percepção. No grupo 7 acreditava-se que algo inesperado poderia acontecer. Foi mantido alto nível de caixa, aceitando-se o custo de oportunidade e a ineficiência financeira. Acreditaram que, por focalizar sua estratégia em preço baixo, não precisariam investir altas somas em Pesquisa e Desenvolvimento [P\&D]. Esqueceram-se de que o investimento em $\mathrm{P} \& \mathrm{D}$, além de melhorar a tecnologia do produto, também reduz os custos de produção, o que apoiaria sua estratégia de produção em escala elevada. Tais comportamentos sugerem falta de retenção das informações na memória e aversão a riscos decorrentes de experiências anteriores.

No grupo 7 acreditava-se que a redução da planta iria melhorar o resultado econômico. Cogitou-se vender equipamentos para reduzir o patrimônio líquido e elevar a taxa interna de retorno. No entanto esta decisão mostrou-se inócua e não alterou o valor do patrimônio líquido, pois a venda dos equipamentos foi transformada em caixa, permanecendo como capital circulante. Após a venda dos equipamentos, o caixa só seria reduzido, se fossem pagos dividendos para reduzir o patrimônio líquido. Isto só seria possível diante de lucros acumulados de períodos anteriores, sinalizando excesso de simplificação na dupla 7.

O cenário econômico no segundo ano de operações foi distinto do primeiro ano de maneira relevante. Além dos diferentes indicadores de inflação e de atividade econômica, houve a regulamentação do novo modelo de produção industrial. Com ele as empresas que desejassem poderiam produzir em até três turnos, sem imobilizar recursos em novos investimentos. O benefício buscado pelo governo tinha duplo caráter: a) estimular o crescimento econômico, gerando benefício social com a oferta de novos empregos e distribuição de renda, em lugar de explorar o regime de horas extras, concentrador de renda, como ocorria no modelo anterior; b) promover aumento da produtividade do parque industrial instalado, propiciando giro dos ativos até $100 \%$ maior. Entusiasmados pelo crescimento da economia durante o primeiro ano de operações, os gestores seguiram aumentando a produção e a oferta de produtos ao mercado. $\mathrm{O}$ crescimento econômico não se sustentou, dando lugar a um período de forte recessão. A euforia do crescimento econômico no primeiro ano tornou-se o viés da experiência passada, que os gestores desejaram que se repetisse no segundo ano, o que não se confirmou, pois o desaquecimento da economia deprimiu a rentabilidade média do setor.

\section{CONSIDERAÇÕES FINAIS}

Os resultados descritos no estudo revelam importantes assimetrias informacionais. Apesar de os grupos assumirem empresas nas mesmas condições iniciais (mesmo ativo e mesma imagem perante o mercado) e de operarem o primeiro ano dos três jogos consecutivos com cenários idênticos, o principal diferencial adveio da capacidade intelectual dos gestores e foi suficiente para produzir desempenhos distintos. Desde o diagnóstico inicial (análise SWOT), após a rodada-teste, cada grupo interpretou os dados e gerou informações assimétricas na tomada de decisão, trazendo evidências de vieses resultantes de:

Experiências passadas 
- Percepção sobre os fatos relatados nos textos e apresentados na abertura

Aversão a riscos decorrentes de perdas anteriores

- Simplificação ou falta de informações importantes, por incapacidade de análise precisa dos dados disponíveis

. Falta de critérios relevantes para resolução de problemas

. Limitação de percepção

- Restrição de tempo e de custo

. Limitação na capacidade de retenção de informações na memória

Em geral nos Jogos de Empresas nota-se que, mesmo partindo de situação inicial idêntica, a análise dos dados iniciais simétricos tende a produzir informações iniciais assimétricas. No decorrer do jogo as decisões são influenciadas pela aprendizagem decorrente das rodadas seqüenciais (racionalidade subjetiva) e pela expectativa de maximizar o desempenho de maneira sustentável (racionalidade objetiva). As diferentes interpretações dos dados históricos (diagnóstico) conduzem a diferentes formulações da estratégia (objetivos, políticas e orçamentos) e, consequientemente, a diferentes resultados: participação de mercado, lucro e taxa de retorno. Diferentes estratégias correspondem a diferentes desempenhos, não sendo possível a todos os grupos maximizar a utilidade, em razão de fatores como incerteza, assimetria de informação, restrição de tempo, racionalidade e inteligência.

Verifica-se que o uso de jogos de empresas para pesquisas experimentais, de acordo com o estudo de Babb et al. (1966), mostrou-se altamente contributivo para a geração de dados primários, porquanto seria difícil observar com tal nível de detalhes o comportamento gerencial e comparar objetivamente os resultados produzidos em empresas do mundo real.

Tanto a Academia como as organizações podem tirar proveito dos relatos oferecidos neste estudo, pois falhas semelhantes às relatadas acima ocorrem diariamente, implicando perdas reais e elevado custo de aprendizagem. Os grupos que erraram menos sustentaram níveis superiores de desempenho econômico. Algumas falhas importantes foram cometidas em decorrência de vieses, prejudicando as empresas de maneira irremediável em alguns casos.

Os processos de comunicação que apóiam as decisões organizacionais carecem de cuidados especiais, não se devendo limitar às exposições orais ou a mensagens apresentadas em palestras a platéias passivas. Os conteúdos das mensagens devem ser retomados de maneira recorrente, para evitar a influência nefasta dos vieses individuais. Um cuidadoso monitoramento da percepção sobre os fatos e da repercussão sobre os grupos deve ser realizado, para evitar que importantes decisões sejam prejudicadas por vieses como simplificação, falta de critério, limitação de percepção, efeitos decorrentes da incapacidade de retenção na memória em ambiente sujeito à restrição de tempo e custos.

Os jogos de empresas, operados como Laboratórios de Gestão, oferecem a baixo custo uma efetiva contribuição, para contrapor-se a modelos prescritivos e descritivos e se evidenciar os limites da racionalidade organizacional em grupos que inadvertidamente podem incorrer em erros sistemáticos. $\mathrm{O}$ reconhecimento por parte das organizações de que tais vieses representam reais ameaças pode promover um novo nível de atenção e prontidão gerencial, reduzindo a incerteza organizacional a níveis aceitáveis de risco e evitando, em alguns casos, que prevaleçam os vieses de julgamento.

\section{Contribuições do Estudo}

A principal contribuição do estudo refere-se aos aspectos metodológicos aqui descritos, em que se fez uso de um ambiente de jogo de empresas, tradicionalmente voltado para a educação gerencial, como um laboratório de pesquisas. Adicionalmente, foram produzidas evidências (dados primários) 
que confirmaram alguns aspectos da teoria da racionalidade limitada de Simon (1976) e de outros pesquisadores laureados que lhe sucederam, como Daniel Kahneman, Amos Tversky e Vernon Smith (Ferreira, 2000). Entender os erros de cognição, identificá-los e classificá-los é essencial para ajudar os gestores a evitá-los no futuro, afirmou Bazerman (2004, p. 173). A conscientização é o primeiro passo, enquanto o segundo passo será a identificação dos erros no próprio comportamento, capacitando-se para prevê-los nas decisões de outros gestores. Vale destacar que o desenho da pesquisa pode ser considerado importante contribuição para replicação e refinamento do estudo.

\section{Limitações do Estudo}

Para Campbell e Stanley (1979, p. 6), os experimentos, se bem-sucedidos, necessitam réplica e validação cruzada em outros tempos, sob outras condições, antes que se possam incorporar à ciência e sejam teoricamente interpretados com confiança. Apesar de se ter realizado o estudo com número reduzido de pessoas, as sete empresas que operaram sob competição oligopolista produziram dados válidos, baseados em observação de comportamentos racionalmente orientados para resultados. Os gestores eram pessoas de elevado nível intelectual, especialistas em gestão, mestrandos e doutorandos com formação na área e com amplo conhecimento da terminologia e dos conceitos, aptos a atuar neste tipo de ambiente. A pesquisa foi realizada somente em uma turma de pós-graduandos, devendo ser replicada em novos experimentos e com outros grupos de gestores. Um único texto e um único simulador foram adotados, podendo ser testadas variações desses dois instrumentos.

De acordo com Binmore (1999) o emprego de métodos experimentais na economia permite consolidar a teoria tradicional nos contextos em que ela funciona bem e inspirar sua revisão na hipótese contrária.

Defender o emprego de métodos experimentais na economia não deve, em hipótese alguma, ser confundido com o endosso do ponto de vista teórico que sustenta os trabalhos realizados no campo da economia experimental. Boa parte da literatura desenvolvida nessa área assenta-se em uma filosofia utilitarista da escolha, cujos pressupostos são discutíveis (p. 150). Parte da literatura experimental apóia-se em pressupostos psicológicos minimalistas, apoiados na idéia de que a escolha revela preferências, e qualquer elemento que desencadeie cursos de ação é redutível ao denominador comum de utilidade. (p. 153)

Quanto ao método experimental e seus procedimentos, reconhecemos que as mudanças introduzidas nos jogos tiveram um impacto positivo sobre a capacidade dos pesquisadores de montar em laboratório sistemas microeconômicos reais, dessa forma construindo um campo de teste adequado para a teoria. À medida que se admite que o jogo de ultimato é incapaz de reproduzir fielmente muitas situações da vida real, ele tem sido substituído por jogos de múltiplos estágios. Da mesma forma, se os jogos que envolvem apenas dois parceiros são pouco representativos das situações reais, podem ser substituídos por jogos de múltiplas pessoas, com as dificuldades técnicas inerentes a essa mudança. Se os participantes do experimento alteram seu comportamento para impressionar favoravelmente o pesquisador, montemos experimentos do tipo "duplo cego", que garantem o anonimato do jogador em relação aos demais jogadores e ao condutor do experimento. Melhor ainda, vamos comparar os resultados do jogo realizado em condições de anonimato com os do mesmo jogo realizado permitindo-se a comunicação entre os parceiros. Boa parte das limitações apontadas podem ser contornadas pelo aperfeiçoamento das regras do jogo, mediante um processo interativo em que os pesquisadores aprendem com seus próprios erros e uns com os outros (Bianchi \& Silva, 2001, pp. 150-151).

Ainda não foi objetivo deste estudo examinar o processo de aprendizagem per se; apesar de central, tem tratamento escasso e caricaturizado (Boerner, Maeher, \& Teece, 2001); tão somente se ponderaram alguns dos efeitos da aprendizagem que sinalizassem a racionalidade na tomada de decisão. Este aspecto poderá ser objeto de novos estudos sob novos desenhos experimentais. Sugere-se como exemplo examinar o extenso estudo de Sauaia (2006). 


\section{Proposições para Novos Estudos}

Bazerman (2004, p. 11) lembra que para Lewin (1947) a mudança no indivíduo não resulta apenas da conscientização de suas imperfeições, mas deve ocorrer continuamente. Para que tenha êxito deve: descongelar processos de decisão existentes; fornecer conteúdos para a mudança; criar condições para recongelar novos processos, tal que a mudança se torne parte do novo repertório-padrão do gestor, até que o novo repertório pereça e o processo se reinicie. Novas pesquisas podem incluir outros experimentos, simuladores e cursos de pós-graduação lato sensu para examinar ambientes, onde a maioria dos participantes seja formada por profissionais. Experimentos em turmas muito numerosas de graduação examinaram outros problemas de pesquisa. Seus resultados sugerem que as limitações da racionalidade humana são recorrentes e têm mostrado presença garantida nos jogos de empresas, oferecendo extraordinária oportunidade para avançar nos estudos dessa natureza.

Artigo recebido em 02.05.2007. Aprovado em 25.06.2008.

\section{REFERENNCIAS BIBLIOGRÁFICAS}

Babb, E. M., Leslie, M. A., \& Van Slyke, M. D. (1966). The potential of business-gaming methods in research. The Journal of Business, 39(4), 465-472.

Barberis, N., \& Thaler, R. (2003). A survey of behavioral finance. In G. M. Constantinides, M. Harris, $\&$ R. Stulz (Eds.). Handbook of the economics of finance. Amsterdam: Elsevier Science B.V. Recuperado em 15 dezembro, 2007, de http://badger.som.yale.edu/faculty/ncb25/ch18_6.pdf

Bazerman, M. H. (2004). Processo decisório. Rio de Janeiro: Campus.

Beppu, C. I. (1984). Simulação em forma de "Jogo de Empresas" aplicada ao ensino da contabilidade. Dissertação de mestrado, Universidade de São Paulo, São Paulo, SP, Brasil.

Bianchi, A. M., \& Silva, G. A., Filho (2001). Economistas de avental branco. Revista de Economia. Contemporânea, 5(2), 129-154.

Binmore, K. (1999). Why experiment in economics? Economic Journal, 109(453), 16-24.

Boerner, C., Macher, J., \& Teece, D. (2001). A review and assessment of organizational learning in economic theories. In M. Dierkes, A. B. Antal, J. Child, \& I. Nonaka (Eds.). Handbook of organizational. learning and knowledge (pp. 89-117). New York: Oxford University Press.

Breinholt, R. H., Chesteen, S. A., \& Cooper, F. W. (1992). The device business: a management simulation for strategy formulation. Proceedings of the Association for Business Simulation and Experiential Learning Conference, Stillwater, Oklahoma, USA, 19.

Breinholt, R. H., Chesteen, S. A., \& Cooper, F. W. (1992). The Device Business: a management simulation for strategy formulation.

Campbell, D. T., \& Stanley, J. C. (1979). Delineamentos experimentais e quase-experimentais de pesquisa. São Paulo: EPU/EDUSP.

Cohen, K. J., \& Rhenman, E. (1961). The role of management games in education and research. Management Science, 7(2), 131-166.

Dasgupta, S., Chanin, M., \& Ioannidis, A. (2000). Research note: group decision making using knowledge-based systems - An experimental study. Simulation \& Gaming, 31(4), 536-544. 
Duncan, R. (1972). Characteristics of organizational environments and perceived environmental uncertainty. Administrative Science Quarterly, 17(3), 313-327.

Faria, A. J., \& Wellington W. J. (2004). A survey of simulation game users, former-users and neverusers. Simulation \& Gaming, 35(2), 178-207.

Ferreira, V. R. M. (2000). A contribuição da psicologia econômica: trajetória e perspectivas de trabalho. Dissertação de mestrado não-publicada, Universidade de São Paulo, São Paulo, Brasil.

Gentry, J. W., \& Schibrowsky, J. A. (1990). A transaction cost analysis of experiential. Learning. Proceedings of the Association for Business Simulation and Experiential Learning Conference, Honolulu, Hawaii, USA, 17.

Gold, S., Strang, C., \& Daniel, R. (1981). The success of a computerized simulation in microeconomic pedagogy. Proceedings of the Association for Business Simulation and Experiential Learning Conference, Orlando, Florida, USA, 8.

Lakatos, E. M., \& Marconi, M. A. (1988). Técnicas de pesquisa. São Paulo: Atlas.

Lima, E. P., \& Lezana, A. G. R. (2005). Desenvolvendo um framework para estudar a ação organizacional: das competências ao modelo organizacional. Gestão \& Produção, 12(2), 177190.

Martinelli, D. P. (1987). A utilização dos jogos de empresas no ensino de administração. Dissertação de mestrado, Universidade de São Paulo, São Paulo, SP, Brasil.

Martins, G. A. (2002). Manual para elaboração de monografias e dissertações. São Paulo: Atlas.

Milanez, D. Y. (2003). Finanças comportamentais no Brasil. Dissertação de mestrado não-publicada, Universidade de São Paulo, São Paulo, SP, Brasil.

Rouchier, J., \& Robin, S. (2006). Information perception and price dynamics in a continuous double auction. Simulation \& Gaming, 37(2), 195-208.

Sauaia, A. C. A. (1989). Jogos de empresas: tecnologia e aplicação. Dissertação de mestrado nãopublicada, Universidade de São Paulo, São Paulo, SP, Brasil.

Sauaia, A. C. A. (1995). Satisfação e aprendizagem em jogos de empresas: contribuições para a educação gerencial. Tese de doutoramento não-publicada, Universidade de São Paulo, São Paulo, Brasil.

Sauaia, A. C. A. (2003, março). Conhecimento versus desempenho das organizações: um estudo empírico com jogos de empresas. Anais do Seminários em Administração, São Paulo, SP, Brasil, 6.

Sauaia, A. C. A. (2005). Gestão da estratégia: um guia prático (Manual do participante do Laboratório de Gestão Empresarial). São Paulo: FEA/USP.

Sauaia, A. C. A. (2006). Lógica econômica, raciocínio estratégico e evolução organizacional: além das regras do jogo de empresas. Tese de livre docência não publicada. Universidade de São Paulo, São Paulo, SP, Brasil.

Sauaia, A. C. A., \& Sylos, A. L. (2000). Plano empresarial em quatro etapas. Caderno de Pesquisas em Administração, 1(11), 1-11.

Shiller, R. J. (2000). Exuberância irracional. São Paulo: Makron.

Shiller, R. J. (2002). From efficient markets theory to behavioral finance [Cowles Foundation Discussion Paper $n^{\circ}$ 1385]. Cowles Foundation for Research in Economics, Yale University. 
New Haven, Connecticut. Recuperado em 15 dezembro, 2007, de http://cowles.econ.yale.edu/P/cd/d13b/d1385.pdf

Simon, H. A. (1957). Models of man. New York: John Wiley.

Simon, H. A. (1976). Administrative behavior. New York: The Free Press.

Tanabe, M. (1973). Jogos de empresas. Dissertação de mestrado não publicada. Universidade de São Paulo, São Paulo, SP, Brasil.

Whitney, G. (1984). A comparison of two business strategy simulations for microcomputers. Proceedings of the Association for Business Simulation and Experiential Learning Conference, Honolulu, Hawaii, USA, 11.

Wolfe, J., \& Castroviovanni, G. (2006). Business games as strategic management laboratories. Proceedings of the Association for Business Simulation and Experiential Learning Conference, San Francisco, CA, USA, 33. 